\title{
Weight changes of younger and older early breast cancer patients - a meta regression
}

\author{
Ronald Chow ${ }^{1,2}$, Charles B. Simone $\mathrm{II}^{2}$, Vicky Ro ${ }^{3}$, Leonard Chiu ${ }^{3}$, Michael Lock ${ }^{1}$ \\ ${ }^{1}$ London Health Sciences Centre, University of Western Ontario, London, ON, Canada; ${ }^{2}$ New York Proton Center, New York, NY, USA; ${ }^{3}$ Columbia \\ University Vagelos College of Physicians and Surgeons, Columbia University, New York, NY, USA \\ Contributions: (I) Conception and design: R Chow, M Lock; (II) Administrative support: CB Simone 2nd, M Lock; (III) Provision of study materials \\ or patients: R Chow; (IV) Collection and assembly of data: R Chow, L Chiu; (V) Data analysis and interpretation: R Chow, V Ro; (VI) Manuscript \\ writing: All authors; (VII) Final approval of manuscript: All authors. \\ Correspondence to: Ronald Chow. New York Proton Center, 225 E 126th St, New York, NY 10035, USA. Email: rchow@nyproton.com.
}

\begin{abstract}
Background Weight gain during chemotherapy for breast cancer is quite common and has a major impact on the quality of life. Post-treatment weight gain can also impact on primary endpoints such as tumor recurrence and overall survival. Parameters thought to impact weight gain include menopausal status, age and chemotherapy regimen. Using meta-regression, we studied the effect of age on weight change by menopausal status and chemotherapy regimen.

Methods: Twenty-four studies were identified, and extracted for weight change, mean/median age, menopausal status and chemotherapy regimen. A meta-regression was performed using a random-effects model for high heterogeneity and fixed-effects inverse-variance model for low heterogeneity. Subgroup analyses by menopausal status and chemotherapy regimen were conducted. $\mathrm{P}$ values $<0.05$ were considered statistically significant.

Results: There exists no relationship between weight change and age $(\beta=0.00 ; P=0.987)$. Stratifying by menopausal status $(\beta=0.05$ and $\mathrm{P}=0.150$ for premenopausal patients; $\beta=0.09$ and $\mathrm{P}=0.588$ for postmenopausal patients) and chemotherapy regimens $(\beta=-0.07$ and $\mathrm{P}=0.562$ for patients receiving $\mathrm{CMF}$ alone; $\beta=0.08$ and $\mathrm{P}=0.707$ for patients receiving $\mathrm{CMF}$ in addition to others; $\beta=0.02$ and $\mathrm{P}=0.807$ for patients not receiving $\mathrm{CMF}$ ), there likewise was no relationship between weight change and age.

Conclusions: Management of weight gain due to chemotherapy has been focused on relatively young women who are generally at higher risk of mortality and tumor recurrence. However, our results suggest that age should not be used for differential care.
\end{abstract}

Keywords: Weight change; early stage breast cancer; chemotherapy; corticosteroids; meta-regression

Submitted Jun 21, 2021. Accepted for publication Aug 20, 2021.

doi: $10.21037 / \mathrm{apm}-21-1650$

View this article at: https://dx.doi.org/10.21037/apm-21-1650

\section{Introduction}

For patients receiving chemotherapy for early-stage breast cancer, weight gain has been frequently reported, and in sizable minority of patients this change in weight can be quite significant $(1,2)$. This weight gain can negatively impact quality of life and self-esteem and lead to inferior clinical outcomes (2). Mechanisms of weight gain include corticosteroid use, edema, decreased physical activity, and changes in menopausal status, from pre-menopause to postmenopause (3). Both the development of increased edema and the increase in fatigue from cancer-directed treatments lead to decreases in physical activity and further perpetuate fatigue. Important changes in body composition (BMI) are especially pronounced in younger women, who can become postmenopausal due to chemotherapy. Despite less weight gain with more recent chemotherapy regimens, this change in BMI continues to impact breast cancer prognosis 
and the development of other medical conditions, such as heart disease, which is a significant cause of mortality in breast cancer survivors (4-7). Additionally, Thivat et al. (8) report that a $5 \%$ or greater weight change is associated with increased risks of recurrence (RR: 2.28, 95\% CI: 1.29-4.03) and death (RR: 2.11, 95\% CI: 1.21-3.66).

Prevalence of weight gain has been reported to occur in between $50-96 \%$ of breast cancer patients. This weight gain can vary from, on average, 1.4 to $6.2 \mathrm{~kg}(9)$. van den Berg et al. (9), in a systematic review and meta-analysis, found that body weight on average increased by $2.7 \mathrm{~kg}$ during chemotherapy. Their sensitivity analyses by study design, menopausal status, chemotherapy regimen and year of publication showed variation in weight gain. However, their review cited high heterogeneity, suggesting that there may be a confounder in their analysis.

Age was previously reported to affect weight gain in a large population-based cohort study of 4,561 patients, where Chen et al. reported that younger breast cancer patients experienced greater weight changes (10). Based on their results, one may infer that studies with younger patients will observe a greater weight change. The observed variations reported by van den Berg et al. (9) by chemotherapy regimen and menopausal status may, therefore, be a confounded observation of age. Clarifying this issue is important, as it will inform whether age of patients should be considered when enacting interventions for weight change. Additionally, it will clarify whether menopausal status and chemotherapy regimen still have an effect on weight change, after accounting for the potential confounder of age. Clarifying these important points can improve the management of breast cancer patients and inform future clinical trials. Therefore, we performed a meta-regression for studies reporting on chemotherapy use in early-stage breast cancer patients to investigate the effect of age in the causal pathway of weight gain and provide clarification on whether age may have been a contributing factor to high heterogeneity in the van den Berg et al. (9) meta-analysis.

\section{Methods}

We searched the databases of Ovid Medline, Embase and Cochrane Central Register of Controlled Trials for studies reporting on weight change in early breast cancer patients using the MeSH headings of "breast neoplasms", "neoplasm staging", and "body-weight trajectory". We identified the same 25 studies for inclusion as those reported by van den Berg et al. (9) in their systematic review. The fulltext for the article written by Foltz (11) was not available, which was one of the 25 papers included by van den Berg et al. (9). Therefore, that paper was excluded from this analysis as pertinent details from the full text article are required for meta-regression, and 24 papers (12-35) were included. As this article is therefore a secondary data analysis of a published review, no PRISMA is reported; characteristics of articles can be reviewed in the van den Berg et al. (9) paper. The effect size of weight gain for each study was extracted and cross-referenced with those reported by van den Berg et al. (9). The age of patients included in the study, as reported using measures of central tendency (mean or median), was noted. Additionally, the menopausal status of patients enrolled in studies were recorded, either as reporting exclusively on (I) premenopausal patients, (II) postmenopausal patients, and (III) premenopausal and postmenopausal patients. Finally, we recorded whether patients received (I) cyclophosphamide, methotrexate, and fluorouracil (CMF) chemotherapy only, (II) CMF chemotherapy, alongside other regimens, or (III) non-CMF other chemotherapy treatment.

\section{Statistical analysis}

A random-effects DerSimonian and Laird model was used when heterogeneity was high $\left(\mathrm{I}^{2}>50 \%\right)$, and fixed-effect inverse-variance model $\left(\mathrm{I}^{2}<50\right)$ was used to meta-regress effect size relative to age of patients. Subgroup analyses were conducted by menopausal status of patients and by chemotherapy treatment. The threshold for statistical significance was specified, a priori, at $\alpha=0.05$. All analyses were conducted using Stata 16.1 (StataCorp, College Station, TX, USA).

\section{Results}

The average age in trials ranged from 39.9 years to 55 years. Six studies $(14,17,18,26,29,33)$ reported on premenopausal patients, four $(12,21,23,25)$ on postmenopausal patients, and fourteen $(13,15,16,19,20,22,24,27,28,30-32,34,35)$ on both premenopausal and postmenopausal patients. Seven $(12,21,23,25,26,32,33)$, nine $(17,18,21-24,30,31,35)$ and twelve studies (13-16,19,21,23,26-29,34) reported on CMF-only, CMF-containing and non-CMF regimens, respectively.

Across all studies, there exists no relationship between weight change and age $(\beta=0.00$ and $\mathrm{P}=0.987)$ (Figure 1). In 
subgroup analyses of premenopausal and postmenopausal patients, there also exists no relationship with $\beta=0.05$ and $\mathrm{P}=0.150$ for premenopausal patients, and $\beta=0.09$ and

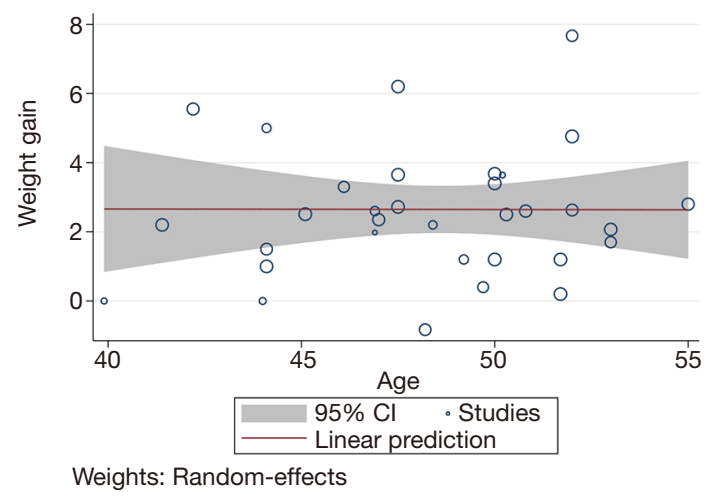

Figure 1 Weight change, as a function of age, in all early breast cancer patients $(\beta=0.00 ; \mathrm{P}=0.987)$. Each circle indicates an individual study's results. The size of the circle denotes the weighting in the meta-regression model. CI, confidence interval.
$\mathrm{P}=0.588$ for postmenopausal patients (Figure 2). When analyzing separately by chemotherapy regimen, there likewise was no relationship between weight gain and age ( $\beta=-0.07$ and $P=0.562$ for patients receiving $C M F$ alone; $\beta=0.08$ and $\mathrm{P}=0.707$ for patients receiving $\mathrm{CMF}$ in addition to others; $\beta=0.02$ and $\mathrm{P}=0.807$ for patients not receiving CMF) (Figure 3).

\section{Discussion}

To our knowledge, this is the first meta-regression reporting on weight change as a function of age. We report on 24 studies, with a total sample size of 2,586 patients with earlystage breast cancer. There is no relationship between age and weight change among early-stage breast cancer patients undergoing chemotherapy across all subgroup analyses. We were able to determine that age is not a confounder in the relationships between chemotherapy regimen and weight change or between menopausal status and weight change.

This study was able to address the common perception

B

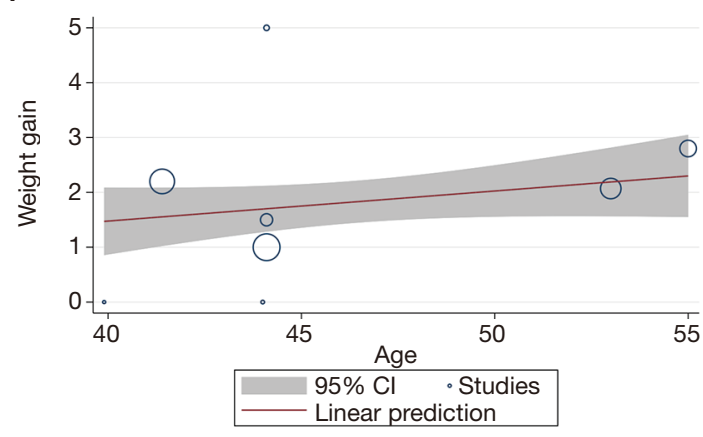

Weights: Inverse-variance

C

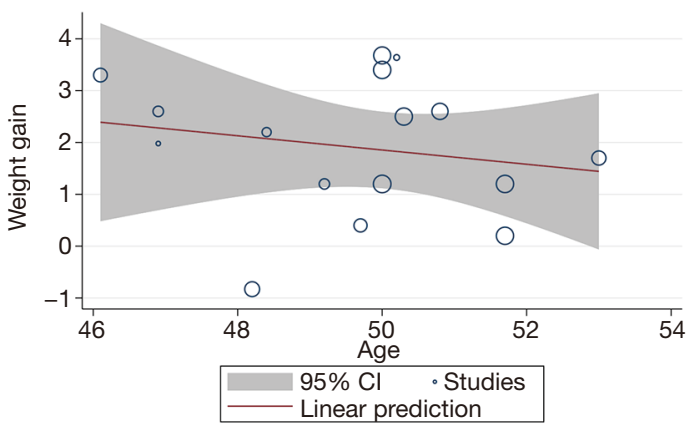

Weights: Random-effects

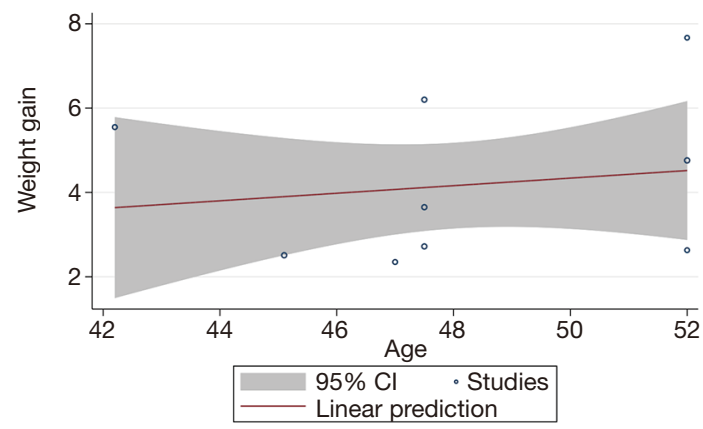

Weights: Random-effects

Figure 2 Weight change, as a function of age, for (A) premenopausal patients $(\beta=0.05 ; \mathrm{P}=0.150)$, (B) postmenopausal patients ( $\beta=0.09$; $\mathrm{P}=0.588),(\mathrm{C})$ premenopausal and postmenopausal patients $(\beta=-0.14 ; \mathrm{P}=0.546)$. Each circle indicates an individual study's results. The size of the circle denotes the weighting in the meta-regression model. CI, confidence interval. 
A

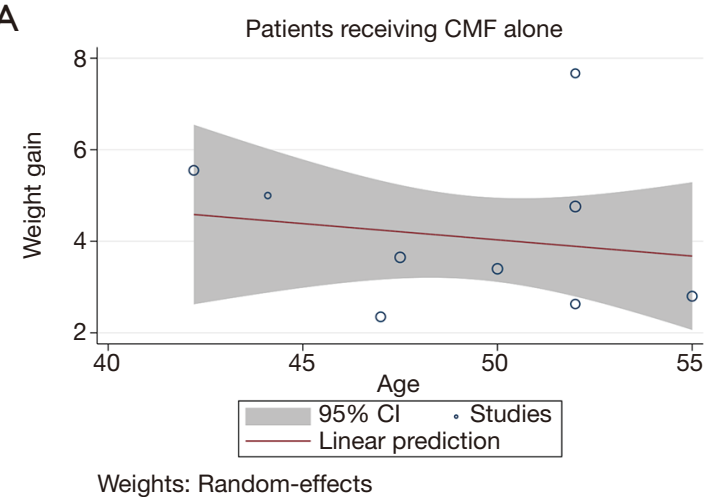

C

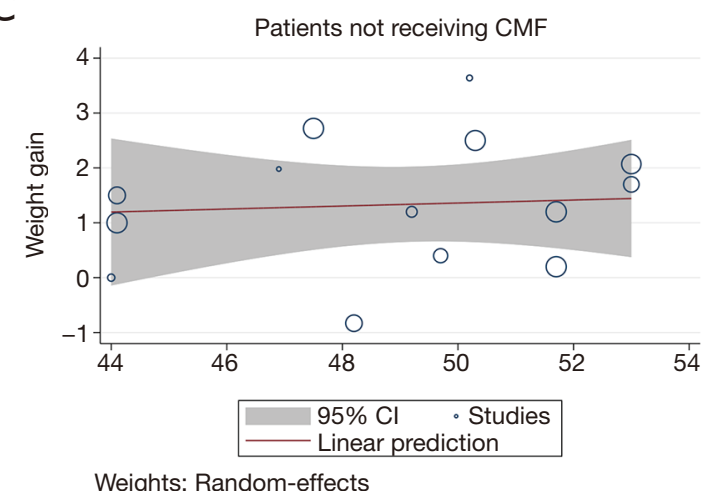

B

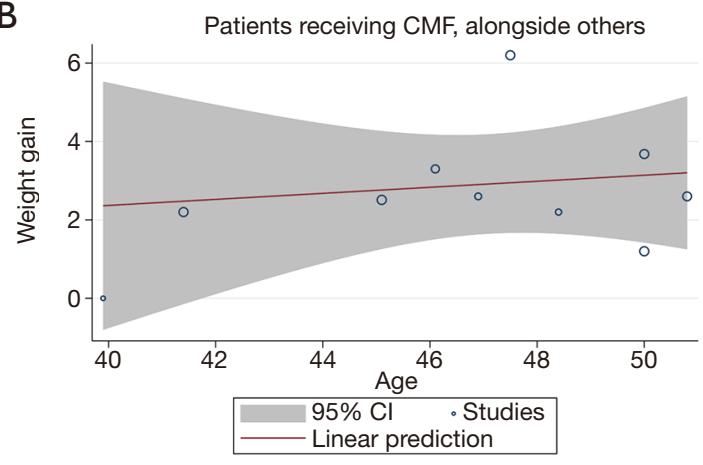

Weights: Random-effects

Figure 3 Weight change, as a function of age, for (A) patients receiving CMF alone ( $\beta=-0.07 ; \mathrm{P}=0.562)$, (B) patients receiving CMF, in addition to others ( $\beta=0.08 \mathrm{P}=0.707)$, $(C)$ patients not receiving $\mathrm{CMF}(\beta=0.02 ; \mathrm{P}=0.807)$. Each circle indicates an individual study's results. The size of the circle denotes the weighting in the meta-regression model. CI, confidence interval; CMF, cyclophosphamide, methotrexate, and fluorouracil.

that weight gain is a larger problem for younger women due to chemotherapy-induced menopause. In contrast, this study reports that both younger and older women experience similar degrees of weight change.

This study also provides further guidance on clinical decision making. Patients often ask about weight gain, and the answer may influence their selection of chemotherapy regimen or even willingness to accept potentially life-saving treatment. Physicians query weight gain as well, as it has a significant impact on patient quality of life, recurrence rates, and even survival. This study provides a means to inform patients with accurate data and to guide physicians in focusing not on age, but rather on other weight gain predictors. Since age is not an independent risk factor for weight gain, decisions on which patients require more intensive intervention for preventing weight gain should be based on evidence from studies exploring body composition, metabolism and insulin resistance instead (5). Given studies demonstrating higher morbidity and mortality among breast cancer patients with higher BMI, patients of all ages, not just younger patients, should be encouraged to maintain a healthy weight following their breast cancer diagnoses. Furthermore, as noted in the prior review by van den Berg et al. (9), different magnitudes of weight gain were noted by menopausal status and chemotherapy regimen (9); these factors should be heavily considered, irrespective of age, when considering intervention options.

A limitation of this study, like other evidence synthesis studies, is that its validity is reliant on the validity of included studies. As reported by van den Berg et al. (9), the included studies were heterogenous and some were not of the highest quality, as assessed using the Newcastle-Ottawa scale. This analysis may also suffer from reporting bias, where only certain age groups are reported in the literature. However, included studies had a wide range of average ages, spanning 15 years. It is also possible that other confounders 
not previously identified or assessed in this analysis may exist affecting weight change in this patient population. As well, we were unable to access one article previously cited by van den Berg et al. (9) and include it in our metaregression.

In conclusion, there is no relationship confounding effect of age on weight change in early-stage breast cancer patients. This was observed among both premenopausal and postmenopausal patients, as well as patients receiving CMF chemotherapy and other chemotherapy regimens.

\section{Acknowledgments}

Funding: None.

\section{Footnote}

Conflicts of Interest: All authors have completed the ICMJE uniform disclosure form (available at https://dx.doi. org/10.21037/apm-21-1650). Charles B. Simone serves as an Editor-in-Chief of Annals of Palliative Medicine. Michael Lock received consulting fees from Ferring. The other authors have no conflicts of interest to declare.

Ethical Statement: The authors are accountable for all aspects of the work in ensuring that questions related to the accuracy or integrity of any part of the work are appropriately investigated and resolved.

Open Access Statement: This is an Open Access article distributed in accordance with the Creative Commons Attribution-NonCommercial-NoDerivs 4.0 International License (CC BY-NC-ND 4.0), which permits the noncommercial replication and distribution of the article with the strict proviso that no changes or edits are made and the original work is properly cited (including links to both the formal publication through the relevant DOI and the license). See: https://creativecommons.org/licenses/by-nc-nd/4.0/.

\section{References}

1. Cheney CL, Mahloch J, Freeny P. Computerized tomography assessment of women with weight changes associated with adjuvant treatment for breast cancer. Am J Clin Nutr 1997;66:141-6.

2. Rock CL, Demark-Wahnefried W. Nutrition and survival after the diagnosis of breast cancer: a review of the evidence. J Clin Oncol 2002;20:3302-16.
3. Davis SR, Castelo-Branco C, Chedraui P, et al. Understanding weight gain at menopause. Climacteric 2012;15:419-29.

4. Vance V, Mourtzakis M, McCargar L, et al. Weight gain in breast cancer survivors: prevalence, pattern and health consequences. Obes Rev 2011;12:282-94.

5. Makari-Judson G, Braun B, Jerry DJ, et al. Weight gain following breast cancer diagnosis: Implication and proposed mechanisms. World J Clin Oncol 2014;5:272-82.

6. Guo A, Zhang KW, Reynolds K, et al. Coronary heart disease and mortality following a breast cancer diagnosis. BMC Med Inform Decis Mak 2020;20:88.

7. Li YR, Ro V, Tchou JC. Obesity, Metabolic Syndrome, and Breast Cancer: From Prevention to Intervention. Curr Surg Rep 2018;6:7.

8. Thivat $\mathrm{E}$, Thérondel $\mathrm{S}$, Lapirot $\mathrm{O}$, et al. Weight change during chemotherapy changes the prognosis in non metastatic breast cancer for the worse. BMC Cancer 2010;10:648.

9. van den Berg MM, Winkels RM, de Kruif JT, et al. Weight change during chemotherapy in breast cancer patients: a meta-analysis. BMC Cancer 2017;17:259.

10. Chen X, Lu W, Gu K, et al. Weight change and its correlates among breast cancer survivors. Nutr Cancer 2011;63:538-48.

11. Foltz AT. Weight gain among stage II breast cancer patients: a study of five factors. Oncol Nurs Forum 1985;12:21-6.

12. Aslani A, Smith RC, Allen BJ, et al. Changes in body composition during breast cancer chemotherapy with the CMF-regimen. Breast Cancer Res Treat 1999;57:285-90.

13. Basaran G, Turhal NS, Cabuk D, et al. Weight gain after adjuvant chemotherapy in patients with early breast cancer in Istanbul Turkey. Med Oncol 2011;28:409-15.

14. Biglia N, Cozzarella M, Ponzone R, et al. Personal use of HRT by postmenopausal women doctors and doctors' wives in the north of Italy. Gynecol Endocrinol 2004;18:165-74.

15. Campbell KL, Lane K, Martin AD, et al. Resting energy expenditure and body mass changes in women during adjuvant chemotherapy for breast cancer. Cancer Nurs 2007;30:95-100.

16. Courneya KS, Segal RJ, Mackey JR, et al. Effects of aerobic and resistance exercise in breast cancer patients receiving adjuvant chemotherapy: a multicenter randomized controlled trial. J Clin Oncol 2007;25:4396-404.

17. Demark-Wahnefried W, Hars V, Conaway MR, et al. Reduced rates of metabolism and decreased physical 
activity in breast cancer patients receiving adjuvant chemotherapy. Am J Clin Nutr 1997;65:1495-501.

18. Demark-Wahnefried W, Peterson BL, Winer EP, et al. Changes in weight, body composition, and factors influencing energy balance among premenopausal breast cancer patients receiving adjuvant chemotherapy. J Clin Oncol 2001;19:2381-9.

19. Freedman RJ, Aziz N, Albanes D, et al. Weight and body composition changes during and after adjuvant chemotherapy in women with breast cancer. J Clin Endocrinol Metab 2004;89:2248-53.

20. Goodwin PJ, Ennis M, Pritchard KI, et al. Adjuvant treatment and onset of menopause predict weight gain after breast cancer diagnosis. J Clin Oncol 1999;17:120-9.

21. Goodwin PJ, Panzarella T, Boyd NF. Weight gain in women with localized breast cancer--a descriptive study. Breast Cancer Res Treat 1988;11:59-66.

22. Harvie MN, Campbell IT, Baildam A, et al. Energy balance in early breast cancer patients receiving adjuvant chemotherapy. Breast Cancer Res Treat 2004;83:201-10.

23. Heasman KZ, Sutherland HJ, Campbell JA, et al. Weight gain during adjuvant chemotherapy for breast cancer. Breast Cancer Res Treat 1985;5:195-200.

24. Heideman WH, Russell NS, Gundy C, et al. The frequency, magnitude and timing of post-diagnosis body weight gain in Dutch breast cancer survivors. Eur J Cancer 2009;45:119-26.

25. Huntington MO. Weight gain in patients receiving adjuvant chemotherapy for carcinoma of the breast. Cancer 1985;56:472-4.

26. Ingram C, Brown JK. Patterns of weight and body composition change in premenopausal women with early stage breast cancer: has weight gain been overestimated? Cancer Nurs 2004;27:483-90.

27. Jeon YW, Lim ST, Choi HJ, et al. Weight change and

Cite this article as: Chow R, Simone CB 2nd, Ro V, Chiu L, Lock M. Weight changes of younger and older early breast cancer patients-a meta regression. Ann Palliat Med 2021;10(10):10222-10227. doi: 10.21037/apm-21-1650 its impact on prognosis after adjuvant TAC (docetaxeldoxorubicin-cyclophosphamide) chemotherapy in Korean women with node-positive breast cancer. Med Oncol 2014;31:849.

28. Kumar N, Allen KA, Riccardi D, et al. Fatigue, weight gain, lethargy and amenorrhea in breast cancer patients on chemotherapy: is subclinical hypothyroidism the culprit? Breast Cancer Res Treat 2004;83:149-59.

29. Kutynec CL, McCargar L, Barr SI, et al. Energy balance in women with breast cancer during adjuvant treatment. J Am Diet Assoc 1999;99:1222-7.

30. Lankester KJ, Phillips JE, Lawton PA. Weight gain during adjuvant and neoadjuvant chemotherapy for breast cancer: an audit of 100 women receiving FEC or CMF chemotherapy. Clin Oncol (R Coll Radiol) 2002;14:64-7.

31. Makari-Judson G, Judson CH, Mertens WC. Longitudinal patterns of weight gain after breast cancer diagnosis: observations beyond the first year. Breast J 2007;13:258-65.

32. McInnes JA, Knobf MT. Weight gain and quality of life in women treated with adjuvant chemotherapy for early-stage breast cancer. Oncol Nurs Forum 2001;28:675-84.

33. Del Rio G, Zironi S, Valeriani L, et al. Weight gain in women with breast cancer treated with adjuvant cyclophosphomide, methotrexate and 5-fluorouracil. Analysis of resting energy expenditure and body composition. Breast Cancer Res Treat 2002;73:267-73.

34. Trédan O, Bajard A, Meunier A, et al. Body weight change in women receiving adjuvant chemotherapy for breast cancer: a French prospective study. Clin Nutr 2010;29:187-91.

35. Winkels RM, Beijer S, van Lieshout R, et al. Changes in body weight during various types of chemotherapy in breast cancer patients. e-SPENJ 2013;9:e39-e44. 